\title{
Tests of Graphic Visuals and Cigarette Package Warning Combinations: Implications for the Framework Convention on Tobacco Control
}

\author{
Jeremy Kees, Scot Burton, J. Craig Andrews, and \\ John Kozup
}

\begin{abstract}
The World Health Organization recently adopted the Framework Convention on Tobacco Control, a groundbreaking public health treaty that will require that warning information in the form of text, pictures, or a combination of these two forms cover at least 30\% of the front and back of cigarette packages. In three studies using smokers from the United States and Canada, the authors examine the effects of specific graphic visuals in the context of current U.S. verbal warnings. The findings indicate that including both graphic visual warnings, such as those used in Canada, and warning statements currently used in the United States can decrease the perceived attractiveness of the package and create higher levels of negative affect, such as fear or anxiety. The results also show that the addition of the specific visual warnings examined to the U.S. statements increases smokers' perceived intentions of quitting smoking compared with warning statements alone. The authors offer implications for public policy and public health and provide suggestions for further research.
\end{abstract}

$\mathbf{M}$ any alarming statistics point to the continued problem of cigarette smoking in the United States and worldwide. An estimated 44.5 million people (20.9\% of all adults) in the United States smoke cigarettes (Centers for Disease Control and Prevention [CDC] 2005a). According to a comprehensive report from the CDC, cigarette smoking alone causes 440,000 premature deaths annually and accounts for $30 \%$ of cancer deaths (CDC 2005b). The global consequences of tobacco use are even more disturbing. There is no other consumer product that kills as many people as tobacco, which is estimated to account for approximately 5 million deaths per year (World Health Organization [WHO] 2005). Moreover, smoking rates are increasing for women worldwide, and rates for men are

Jeremy Kees is Assistant Professor of Marketing (e-mail: jeremy. kees@villanova.edu), and John C. Kozup is Assistant Professor of Marketing and Director of the Center for Marketing and Public Policy Research (e-mail: john.kozup@villanova.edu), Department of Marketing, Villanova School of Business, Villanova University. Scot Burton is Professor and Wal-Mart Chair in Marketing, Department of Marketing and Logistics, Sam M. Walton College of Business, University of Arkansas (e-mail: sburton@walton.uark.edu). J. Craig Andrews is Professor and Charles H. Kellstadt Chair in Marketing, Department of Marketing, College of Business Administration, Marquette University (e-mail: craig.andrews@marquette.edu). The authors thank MSI International, a full-service marketing intelligence firm based near Philadelphia, for the generous contribution of its survey programming and Internet survey panel for data collection in Studies 2 and 3. The authors also thank Judith P. Wilkenfeld, National Center for TobaccoFree Kids, for helpful comments in the early stages of their research.

(C) 2006, American Marketing Association

ISSN: 0743-9156 (print), 1547-7207 (electronic) increasing in most low- and middle-income countries. Although some 1.1 billion people worldwide currently smoke, the number is projected to rise to more than 1.6 billion by 2025 (World Bank 1999). Worldwide, approximately one-half of all long-term smokers will die from tobacco-related diseases (WHO 2005).

Given the magnitude of these global statistics related to tobacco consumption consequences, in May 2003, the WHO adopted the Framework Convention on Tobacco Control (FCTC), a groundbreaking public health treaty to control tobacco supply and consumption. The treaty contains a "labeling" element that requires health warning information to cover at least $30 \%$ of the principal display areas and, ideally, $50 \%$ or more on tobacco packaging (WHO 2003, Article 11, p. 7). The warning information may take the form of text, visual information, or a combination of the two.

By November 2004, the minimum number of countries (40) necessary to bring the FCTC into force had ratified the treaty. On February 27, 2005, the FCTC became international binding law, requiring all countries that ratified it to take steps to abide by its provisions. Within a period of three years after the FCTC's entry into force, there will be specific labeling requirements for warnings on cigarette packaging for countries that ratified the treaty. As of September 2006, the FCTC had been signed by 168 countries and ratified by 137 . The treaty remains open for ratification, approval, and formal confirmation indefinitely for any countries that want to become parties to it. Potentially, the FCTC represents the beginning of an extraordinary era for tobacco control; it is anticipated that many countries all over the world will implement important new policies, including stronger warning labels, restrictions on advertising and promotion, and increased tobacco taxation (Fong 2003). 
Since December 2000, and consistent with some of the treaty's provisions, federal policy in Canada has required warning information to consist of both strong text and a graphic picture that conveys the harmful health consequences of smoking (e.g., pictures of a diseased mouth, a lung tumor, a brain after a stroke, a damaged heart) and to take up at least $50 \%$ of the front and back panels of cigarette packages. In January 2002, Brazil implemented a cigarette warning label policy similar to that of Canada. As of March 2006, tobacco products sold in Australia are required to display 1 of 14 new health warnings that consist of graphic images and explanatory messages (Commonwealth of Australia Law 2005). In the European Union, it has been recommended that pictorial health warnings should be made mandatory on both the front and the back of all tobacco products, covering at least $50 \%$ of each of the surfaces (Aspect Consortium 2004).

Given the FCTC's package-warning options, many countries from around the world will likely be considering revisions to cigarette warning label policies to conform to FCTC guidelines. Because the FCTC provides the option of using text and/or visual warnings, studies examining effects of specific warning alternatives used in practice will be useful to "frontline" policy makers and public health officials as they consider what types of warning information should be required on cigarette packages. Therefore, the focus of this research is on specific graphic visuals in the context of verbal warnings currently used in the United States. Specifically, we examine how the inclusion of two pictorial warnings in addition to two warning statements currently used in the United States affects the evaluations and smokingrelated intentions among samples of both young and adult smokers. This assessment is similar to commercial advertising copy tests that use forced exposure to stimuli of interest but also include control groups not exposed to certain conditions in question (see Andrews and Maronick 1995; Maronick 1991). Our three studies examine two specific visual warnings, two warning statements currently used in the United States, and a series of control groups to determine whether the visual warnings contribute to any incremental effects beyond that found for the current U.S. warning statements.

\section{Background and Literature Review}

\section{Cigarette Package Warning Labels}

It is well known that packaging can be an important promotional tool for marketers in helping create favorable brand images and links to other strategic marketing elements (see Kotler and Keller 2006; Underwood 1996). To enhance brand value, marketers strive to develop attractive packages that create a desirable brand positioning and to reinforce promotional messages conveyed through integrated marketing communications (Shimp 2007). Because some argue that, at times, a package may provide a more positive promotional effect than advertising (Perreault and McCarthy 1999), marketers strive to create packages that are viewed positively and enhance purchase intentions.

For products that are potentially hazardous to consumers, warnings and disclosures on packages are potentially important communication tools that are available for public health policy and governmental agencies (Bettman, Payne, and Staelin 1986; Stewart, Folkes, and Martin 2001). Such warning and disclosure information can inform consumers about the risks and potential dangers related to product usage and, in turn, counterbalance positive consequences derived from effective package design and other promotion. For tobacco use, key policy issues include informing consumers of the risks of smoking, attempting to persuade smokers to curtail their smoking behavior, and helping prevent nonsmokers from becoming smokers. Warning labels are perceived by public health researchers as part of the educational process designed to provide information to consumers to influence attitudes, intentions, and behavior (Bettman, Payne, and Staelin 1986; Slovic 2001). A recent meta-analysis of empirical warning label research found that warnings can influence several effectiveness dimensions; however, "the ideal combination of warning factors has yet to be identified" (Argo and Main 2004, p. 204).

In response to health and safety hazards associated with tobacco use, the U.S. Congress passed the Federal Cigarette Labeling and Advertising Act (1965) in an attempt to establish a comprehensive federal program to address the issue of cigarette labeling and advertising with respect to the relationship between smoking and health. This law was amended in 1984 (Comprehensive Smoking Education Act) and requires manufacturers, packagers, and importers to print a rotation of four warnings on all labels of imported and domestic cigarettes for sale and distribution in the United States. These warnings include "Quitting Smoking Now Greatly Reduces Serious Risks to Your Health" and "Smoking by Pregnant Women May Result in Fetal Injury, Premature Birth, and Low Birth Weight." These cigarette warning messages are some of the most widely used disclosures mandated by U.S. federal policy and were designed to play a key role in the government's campaign to alert consumers to the dangers of smoking.

Prior cigarette warning research in marketing has covered an array of different topics. For example, research has addressed the effect of warning statements on plain white packages versus regular packaging (Goldberg et al. 1999). In general, the recall of warning information on the plain packages, which removed any brand-related identification and promotional material, was superior to the regular packaging. In a study of the believability of cigarette warning labels, Beltramini (1988) finds that the strength of consumers' smoking attitudes can influence warning label believability. People who held strong beliefs that smoking is harmful reported significantly higher levels of believability of warning labels than those who had less firm beliefs. Findings from a study of newly developed labels derived from adolescent focus groups indicated that the novel warnings (e.g., new formatting and information, such as "Smokers inhale carbon monoxide" and "Cigarettes kill: One in every 3 smokers will die from smoking") targeted at young people are more effective at being noticed and communicating the dangers of smoking than the federally mandated U.S. cigarette warning labels (Fisher et al. 1993).

Although many countries have taken a proactive strategy in attempting to develop more effective warning label policies to change smoking behavior and curtail smoking initiation, direct empirical evidence of the effectiveness of specific features, such as the use of graphic pictures, is not 
abundant. Since December 2000, Canadian federal law has required that all manufacturers and importers of cigarettes to Canada put a warning message and a picture on the front and back of the package. A series of reports based on crosssectional surveys commissioned by Health Canada in 1999 indicates that larger health-warning messages with more emotional content may be more effective in encouraging smokers to stop smoking (Environics Research Group 2003). Data from a 2001 Canadian Cancer Society survey (see Environics Research Group 2001) of more than 2000 Canadian adults (633 of whom were smokers) indicate that $90 \%$ had noticed the new warnings. Among smokers, $43 \%$ indicated that the warnings raised their concerns about the health effects of smoking (Martens 2002). In addition, a substantial number of surveyed Canadian smokers reported that the labels had made them smoke less (Hammond et al. 2004). Although there has not been causal evidence that the new Canadian warnings directly affect smoking attitudes and behavior, approximately one year after the warnings were introduced, cigarette sales dropped by $5.2 \%$, the largest decline in a decade (Martens 2002).

\section{Overview of the Research}

Although these cross-sectional findings seem promising, we believe that other methodologies, such as package test experiments, may help provide additional information about the effects of graphic visuals and warning message combinations on consumers' evaluations and intentions. Such forced-exposure tests involving currently used messages and visuals are potentially useful to public health officials worldwide as they consider revisions to cigarette warning labels as suggested by the FCTC. In Study 1, we focus on young adult smokers, a primary target market of interest for most antismoking campaigns. In Studies 2 and 3, we measure reactions from nonstudent adult smokers from two countries, one that is not familiar with the use of graphic visual warnings (the United States) and one that is familiar (Canada). Thus, our research examines these issues in three package test studies, in which we manipulate both picture and warning statement information conditions.

The primary goal of this research is to study the effects of inclusion of specific visual warnings (e.g., as used in Canada) in combination with existing verbal warning statements currently used in the United States on smokers' evaluations and smoking-related intentions. Across the three studies, we examine two warning statements located on the front of a package stimulus and currently in use in the United States. The first message statement indicates that smoking can cause serious health risks, and the second message pertains to the risks of smoking while pregnant. For these messages, we examine the inclusion of specific graphic visual warnings (e.g., pictures of diseased lungs, a newborn with health problems) that are consistent with these respective message statements. Examples of the particular message statements and visual warnings used appear in the Appendix.

\section{Package Attractiveness and Negative Affect}

In each of the three studies, we address effects of the warning information on consumers' perceptions of package attractiveness and negative affect. Visual stimuli (e.g., pic- tures) are used extensively in advertising to convey information about a brand, to show its uses, and to create an image for the brand (Runyon 1979). In general, research has demonstrated the positive effects of pictures used in advertisements on memory and consumer attitudes (Kisielius and Sternthal 1984; Mitchell and Olson 1981), though in some cases, positive effects of vivid images have not materialized or have been shown to be situational (Frey and Eagly 1993; Taylor and Thompson 1982). However, the literature on emotional appeals in persuasion and advertising (e.g., Agres, Edell, and Dubitsky 1990; Hirschman and Stern 1999; Holbrook and Batra 1987) and survey results of Canadian smokers indicate that adding graphic visuals (e.g., a diseased lung) to packages tested in our research may stimulate a negative affective response (i.e., a sense of fear, uneasiness, or anxiety) and lower perceptions of package attractiveness. For example, $44 \%$ of Canadian smokers surveyed reported some "fear" related to the Canadian labels (Hammond et al. 2004).

\section{Perceived Effectiveness and Smokers' Intent-to- Quit Perceptions}

Because common goals for antismoking messages include influencing consumers' perceptions and intentions to quit, we also examine measures of the perceived effectiveness of the warning and perceived personal intentions to quit. ${ }^{1}$ Such measures have played an important role in antismoking campaign efforts (see Netemeyer, Andrews, and Burton 2005). On the basis of the persuasive imagery literature (e.g., Miniard et al. 1991; Scott and Batra 2003; Smith 1991) and the impact of emotional content as compared with more well-known rational arguments, we posit that packages that include a graphic visual may be perceived as more effective than packages the do not include such a visual.

As we noted previously, the FCTC permits warning statements, visual warnings, or a combination of the two types of warnings on a package. This research assesses the value of adding visual warnings that are used in other countries to warning statements that are currently used in the United States. These types of tests should provide frontline decision makers with information about the value of including graphic visuals as they attempt to develop effective warnings to be displayed on cigarette packaging. In each of the three studies, we use planned comparisons to address the effects of the different possible warning options examined in our studies on the general effectiveness of the warning and smokers' perceived intentions to quit smoking.

\section{Study 1}

\section{Methodology}

\section{Pretests}

Before our package test studies, we conducted two pretests. The objective of the first pretest was to determine the appro-

${ }^{1}$ To test our predictions about warning effectiveness, we use two separate dependent variables; one is a general measure of the effectiveness of the package to encourage smokers to quit and nonsmokers not to smoke, and one is a more specific measure of smokers' personal intentions to quit smoking. We discuss details of these two measures in the "Dependent Measures" subsection. 
priate warning messages and visuals to use in Study 1. One hundred twenty-two undergraduate students at a major southern university participated in a 3 (visual) $\times 7$ (warning message) within-subjects experiment. The findings indicated that a visual of cancerous lungs, which is currently used on packages in Canada, communicated the danger of smoking and was shown in the pretest to be consistent with the meaning communicated by the current U.S. warning statement selected for use in Study 1.

We conducted a second pretest to examine whether a package bearing an actual brand name would be appropriate to use in the main studies. We manipulated the brand name used on the package to test whether package evaluations and attitudinal variables varied across familiarity levels with the use of a familiar cigarette brand, a less familiar brand, and a fictitious brand. Seventy undergraduate students from a major midwestern university participated in a 3 (cigarette brand) $\times 2$ (picture present or absent) between-subjects design. The results indicated that the brand name did not affect key attitudinal- and intentions-dependent measures ( $F$ values ranged from .02 to $2.69, p>.10$ ) and did not interact with the picture factor. Given these findings, we used the Camel package in the main study to increase realism and for policy interest and considerations (see Cohen 2000). ${ }^{2}$

We considered several criteria in selecting the message statement and visual stimulus for use in Study 1. To maximize realism and potential interest for public health policy and the FCTC provisions, we used a statement currently in use in the United States and a visual (picture of lungs with cancer) currently in use in Canada. (Despite the benefits of using highly relevant stimuli that are currently in use, the use of only one verbal warning and one visual restricts generalizations to a broad set of verbal or visual warnings.) As we noted previously, pretests indicated that the picture used was perceived to be consistent with the message statement chosen, and both the message and the picture pertained to disease risk related to smoking.

\section{Package Test Study Design and Participants}

We tested the visual and warning statement manipulations in the context of a four-color mock package of cigarettes with the warning label information (message and picture) presented on the front panel of the package. This approach is analogous to ad copy tests that use forced exposure to stimuli of interest but also include control groups that are not exposed to certain conditions in question (see Andrews and Maronick 1995). Trade-offs are likely to exist in the use of a forced-exposure setting (ensuring attention), with the types of controls used, and with the specific stimuli used (Maronick 1991). The warning message in Study 1 is currently featured on cigarette packages in the Untied States: “SURGEON GENERAL'S WARNING: Quitting Smoking Now Greatly Reduces Serious Risks to Your Health." The visual that we used in Study 1 is currently displayed on packages in Canada and consists of a picture of a pair of cancerous lungs (see the Appendix).

Each warning label was professionally designed and prominently displayed in color on the front of a mock pack-

\footnotetext{
${ }^{2}$ Methodological details and more specific findings for these two pretests are available from the first author on request.
}

age of cigarettes, consistent with FCTC requirements (and in contrast to U.S. warning statements, which are currently displayed on the side of cigarette packages). All other package information (e.g., the number of cigarettes in the package, brand information) was invariant across conditions. In addition, the warning information covered at least $30 \%$ of the front of the package (as required by the FCTC) in all conditions. Study 1 participants were student smokers recruited from classes at a major southern university in the United States; they were paid five dollars for their voluntary participation. At the end of class, smokers who wanted to participate were provided with a packet that contained the survey and experimental package stimulus. Instructions indicated that the questionnaire contained questions about their opinions regarding the package of cigarettes shown on the stimulus without specifying anything related to the picture or warning statement on the package. A total of 76 students participated. To be eligible, participants were required to have smoked cigarettes in the past month on at least one or two occasions, and more than $90 \%$ of those who agreed to participate reported that they had smoked cigarettes a minimum of six days or more in the past month. On days when they smoked, approximately 9 of 10 (88\%) smoked a minimum of several cigarettes a day. The mean age was 22 years, and $99 \%$ were 26 years of age or younger. More than one-half $(59 \%)$ of the participants were male.

We used a $2 \times 2$ between-subjects design in Study 1 . The visual warning conditions included no picture versus the picture of a pair of lungs diseased from cancer (sample sizes of 41 and 35, respectively). The warning statement conditions included no warning statement versus a current U.S. warning (sample sizes of 41 and 35, respectively) assessed in the first pretest. We randomly assigned participants who agreed to participate to the conditions.

\section{Dependent Measures}

Similar to commercial copy tests, the study addressed evaluations of the package and specific effectiveness and smoking-related intention measures assessed immediately after forced exposure to package stimuli. To measure the negative affect associated with the package information, we used five seven-point bipolar adjective scales. We asked respondents to indicate how information on the package made them "feel" with items drawn from prior studies on negative affect (Maheswaran and Meyers-Levy 1990; Watson, Clark, and Tellegren 1988). The endpoints for the items were "anxious/not anxious at all," "nervous/not nervous at all," "fearful/not fearful at all," "uneasy/not uneasy at all," and "upset/not upset at all." We reverse-scored these items so that higher values indicated higher levels of negative affect. The coefficient alpha for this scale was .93. We used two seven-point bipolar adjective scales to measure package attractiveness. Endpoints for the items were "unattractive/ attractive" and "unappealing/appealing." The correlation between these two items was .79 .

We used two dependent measures to examine the overall effectiveness of the package: the perceived effectiveness of the package to encourage other current smokers to quit and to prevent nonsmokers from starting and a more specific measure of personal intentions to quit smoking. To assess the perceived effectiveness of the package to encourage 
other current smokers to quit and to prevent nonsmokers from starting, we used a five-item scale anchored by "strongly agree/strongly disagree." Items included "I think the design of this package of cigarettes would help discourage teenagers from trying smoking," "I think the design of this package of cigarettes would help discourage adults that do not smoke from starting to smoke," "I think the design of this package of cigarettes would help encourage current college-aged smokers to quit," "I think the design of this package of cigarettes would help encourage current adult smokers between 25 and 50 years of age to quit," and "I think the design of this package of cigarettes would help encourage current adult smokers over 50 years of age to quit." The coefficient alpha of this scale was .88 .3

For this sample of smokers, there was substantial interest in a measure related to perceived personal intentions to quit smoking. For this measure, we used two seven-point items $(\mathrm{r}=.91)$ : "The information presented on this package would help me quit smoking," and "Information shown on this package motivates me to quit smoking." 4 Measures of internal consistency for the multi-item measures were all acceptable (Nunnally and Bernstein 1994).

\section{Results}

To examine effects of the message statement and visual information factors, we performed an analysis of covariance with follow-up contrasts. We used attitude toward the brand as a covariate in the three studies.5 Mean values and standard deviations for Study 1 appear in Table 1.

\section{Negative Affect and Package Attractiveness}

Univariate findings show a significant effect of the visual information factor on negative affect $(\mathrm{F}=4.24, p<.05)$. Means indicate that the picture condition $(\mathrm{M}=4.15)$ generates higher levels of negative affect than the no-visual condition $(\mathrm{M}=3.39)$. Univariate effects also indicate that the presence of visual information significantly decreases perceptions of package attractiveness $(\mathrm{M}=3.67$ versus 2.02 ; $\mathrm{F}=28.42, p<.01)$. These results indicate that the use of a visual warning on the front of packages results in higher levels of negative affect and lower evaluations of package attractiveness than packages without a visual.

\section{Perceived Effectiveness and Smokers' Intent-to-Quit Perceptions}

Univariate results show that the effects of the visual information manipulation are significant for both the measure of

\footnotetext{
${ }^{3}$ We performed separate analyses also using this series of questions as two distinct constructs that measured the (1) ability to encourage other people to quit and (2) ability to discourage other people from starting. The findings were identical to that of the single construct that used all five items at once. Because the results did not differ and the correlation between the two measures was high, we opted to treat the items as a single construct.

${ }^{4}$ The correlation between the ability-to-persuade-others measure and the personal-intentions measure was .69, suggesting that slightly less than $50 \%$ of the variance of one dependent variable could be explained by the other.

5 Although pretest findings suggested that the Camel brand was perceived as neutral, in Study 1, there were some effects of brand attitude on the dependent variables. Thus, we partitioned out consumers' attitude toward the brand before examining the effects of the treatments. Consistent with the assumptions of covariance analyses, brand attitude did not interact with the manipulated independent variables.
}

perceived effectiveness to encourage others to quit or not to start $(\mathrm{F}=26.96, p<.01)$ and the more specific measure of perceived personal intentions to quit smoking $(\mathrm{F}=29.22$, $p<.01)$. As Table 1 indicates, inclusion of the picture increases perceived effectiveness and intentions to quit smoking. As we expected, univariate findings also show a main effect for the verbal warning statement such that inclusion of the warning statement increases the perceived effectiveness to encourage others to quit smoking and also the perceived personal intentions to quit smoking $(F s=15.81$ and $19.16, p s<.01$, respectively). ${ }^{6}$

Given different warning label options in the FCTC, we used planned comparisons to assess packages containing (1) both visual and message statements, (2) only visuals, (3) only message statements, and (4) no warning information at all. (Note that the superscripts adjacent to the means in Table 1 are relevant to these comparisons.) For this sample of young smokers, the mean personal-intentions-to-quit score for the condition with both the warning statement and the visual warning $(\mathrm{M}=5.53)$ is significantly greater than those for the U.S. warning-only condition $(\mathrm{M}=3.64, p<$ $.01)$, the visual-warning-only condition $(\mathrm{M}=3.97, p<.01)$, and the no-warning control $(\mathrm{M}=1.72, p<.01)$. We obtained similar results for the ability to encourage others to quit or not to start. The mean reported encourage-to-quit score for the condition with both the warning statement and the visual warning $(\mathrm{M}=4.82)$ is significantly greater than that for each of the three other means (ranging from 1.92 to $4.00 ; p s<.05$ or better). Finally, as we expected, the visualwarning-alone and the message-statement-alone conditions are more effective at increasing personal intentions to quit $(p<.05)$ than no warning information at all.

\section{Discussion}

Although any conclusions drawn should be considered in the context of the study's manipulations, forced exposure to stimuli, particular visuals and message warnings used, and specific (nonbehavioral) measures, the results suggest that the inclusion of a visual on cigarette packages can be more effective than the U.S. verbal warning alone. The findings also suggest that the addition of the specific graphic visual information to the U.S. warning message on a package decreases the perceived attractiveness of the package and creates higher levels of negative affect, such as fear and anxiety. More important, the results also indicate that using visual information, such as the picture used in this study, in conjunction with a current U.S. warning statement increases smokers' perceptions of the influence of the package on their personal intentions to quit and their perceptions of encouraging other smokers to stop or discouraging nonsmokers from trying smoking. Given these findings for this combination of both visual and message warning for a sample of student smokers, Study 2 extends Study 1's results to a nonstudent, adult sample of smokers, using a second message currently used in the U.S. and a different visual warning.

\footnotetext{
${ }^{6}$ As a reviewer noted, readers should use caution in making direct comparisons of these findings with the effectiveness of the current U.S. warning statement, given that the verbal warning in our study was displayed on the front of the package (consistent with the FCTC) rather than on the side panel of the package, where it is now displayed on U.S. cigarette packages.
} 
Table 1. Study 1: Cell Means (Standard Deviations) for Dependent Variables

\begin{tabular}{|c|c|c|c|c|}
\hline Dependent Variables & $\begin{array}{c}\text { A: No } \\
\text { Message/No } \\
\text { Visual } \\
\end{array}$ & $\begin{array}{c}\text { B: No } \\
\text { Message/Visual } \\
\text { Present }\end{array}$ & $\begin{array}{l}\text { C: Message } \\
\text { Present/No } \\
\quad \text { Visual } \\
\end{array}$ & $\begin{array}{c}\text { D: Message } \\
\text { Present/Visual } \\
\text { Present }\end{array}$ \\
\hline \multicolumn{5}{|l|}{ Affective Variables } \\
\hline Negative affect & $2.84(1.87)^{\mathrm{c}, \mathrm{d}}$ & $3.40(1.64)^{\mathrm{d}}$ & $4.09(1.68)^{\mathrm{a}}$ & $4.94(1.41)^{\mathrm{a}, \mathrm{b}}$ \\
\hline Package attractiveness & $4.57(1.49)^{\mathrm{b}, \mathrm{c}, \mathrm{d}}$ & $2.61(1.58)^{a, d}$ & $2.86(1.39)^{\mathrm{a}, \mathrm{d}}$ & $1.32(.66)^{\mathrm{a}, \mathrm{b}, \mathrm{c}}$ \\
\hline \multicolumn{5}{|l|}{ Perceived Effectiveness and Intentions to Quit } \\
\hline $\begin{array}{l}\text { Encourage others to quit/discourage others from } \\
\text { starting }\end{array}$ & $1.92(1.10)^{\mathrm{b}, \mathrm{c}, \mathrm{d}}$ & $4.00(1.62)^{\mathrm{a}, \mathrm{d}}$ & $3.64(1.52)^{\mathrm{a}, \mathrm{d}}$ & $4.82(1.36)^{\mathrm{a}, \mathrm{b}, \mathrm{c}}$ \\
\hline Perceived intentions to quit smoking themselves & $1.72(1.41)^{\mathrm{b}, \mathrm{c}, \mathrm{d}}$ & $3.97(2.08)^{\mathrm{a}, \mathrm{d}}$ & $3.64(2.15)^{\mathrm{a}, \mathrm{d}}$ & $5.53(1.30)^{\mathrm{a}, \mathrm{b}, \mathrm{c}}$ \\
\hline
\end{tabular}

\section{Study 2}

\section{Methodology}

Although the focus of Study 2 centered on combinations of visual and message statement warnings in a forced-exposure context (as in Study 1), the message and visual warnings used were different in that they pertained to the effects of smoking while pregnant. The following warning message displayed on the front panel of the package stimuli in Study 2 is currently used in the United States: "SURGEON GENERAL'S WARNING: Smoking by Pregnant Women May Result in Fetal Injury, Premature Birth, and Low Birth Weight." The visual for Study 2 is consistent with pregnancy-related visuals used in countries that employ graphic visuals on packages and features a picture of a newborn baby with health problems (see the Appendix).

Consistent with Study 1, Study 2 was a 2 (warning message: present or absent) $\times 2$ (visual warning: present or absent) between-subjects design. Again, we presented manipulations in the context of a four-color mock package of cigarettes with the package warning information (message and picture) presented on the front panel of the package, as required by the FCTC. Again, we randomly assigned participants to the conditions.

Participants were members of a nationwide, Web-based research panel administered by a professional market research firm and were entered into a prize drawing as compensation for participation in the study. Similar to Study 1, we instructed participants to answer questions about their opinions regarding the package of cigarettes shown on their computer screen without specifying any information related to warning information. Given that the warning information used in Study 2 was focused primarily on risk related to smoking while pregnant, participants in this study were restricted to women in the United States between the ages of 18 and 44. As in Study 1, all participants were current smokers. A total of 199 female smokers participated, and we randomly assigned them to the treatment conditions. Twothirds of the participants had at least some education beyond high school, and slightly more than one in five were college graduates.

\section{Dependent Measures}

Measures of negative affect and package attractiveness were identical to those used in Study 1. We collected similar measures of perceived effectiveness and perceived personal intentions, but we adapted these measures slightly to increase the relevancy to the female sample and type of smoking risk. For example, in Study 2, we measured perceived effectiveness of the package to encourage other smokers to quit with a three-item scale anchored by "strongly agree/strongly disagree." Items included "I think the design of this package of cigarettes would help discourage current college-aged female smokers to quit," "I think the design of this package of cigarettes would help motivate pregnant women who normally smoke to not smoke while they are pregnant," and "I think the design of this package of cigarettes would help encourage pregnant women smokers to quit." The coefficient alpha for this scale was .89. We measured perceived personal intentions to quit smoking with three items: "The information presented on this package would help me quit smoking," "Information shown on this package motivates me to quit smoking," and "If I were pregnant, this package would discourage me from smoking." The coefficient alpha for this scale was .83 .

\section{Results}

Consistent with Study 1, we performed analyses of covariance with follow-up contrasts. Mean values and standard deviations for Study 2 appear in Table 2. We discuss the univariate results and contrasts for the dependent variables subsequently.

\section{Negative Affect and Package Attractiveness}

The univariate interactions between the message statement and the visual warning factors are nonsignificant for both negative affect and package attractiveness ( $p$ s $>.10)$. However, univariate findings show a significant main effect for visual information on both negative affect $(\mathrm{F}=22.40, p<$ $.01)$ and package attractiveness $(\mathrm{F}=72.63, p<.01)$. As in Study 1, mean scores indicate that the presence of this particular visual warning creates more negative affect $(\mathrm{M}=$ 
Table 2. Studies 2 and 3: Cell Means (Standard Deviations) for Dependent Variables

\begin{tabular}{|c|c|c|c|c|}
\hline Dependent Variables & $\begin{array}{c}\text { A: No } \\
\text { Message/No } \\
\text { Visual }\end{array}$ & $\begin{array}{c}\text { B: No } \\
\text { Message/Visual } \\
\text { Present }\end{array}$ & $\begin{array}{c}\text { C: Message } \\
\text { Present/No } \\
\text { Visual }\end{array}$ & $\begin{array}{c}\text { D: Message } \\
\text { Present/Visual } \\
\text { Present }\end{array}$ \\
\hline \multicolumn{5}{|c|}{ Study 2} \\
\hline \multicolumn{5}{|l|}{ Affective Variables } \\
\hline Negative affect & $3.23(1.53)^{b, d}$ & $4.41(1.37)^{\mathrm{a}, \mathrm{c}}$ & $3.19(1.61)^{\mathrm{b}, \mathrm{d}}$ & $4.34(1.71)^{\mathrm{a}, \mathrm{c}}$ \\
\hline Package attractiveness & $3.68(1.42)^{b, d}$ & $1.64(1.25)^{\mathrm{a}, \mathrm{c}}$ & $3.80(1.85)^{b, d}$ & $1.82(1.49)^{\mathrm{a}, \mathrm{c}}$ \\
\hline \multicolumn{5}{|l|}{ Perceived Effectiveness and Intentions to Quit } \\
\hline Encourage other smokers to quit & $2.78(1.57)^{\mathrm{b}, \mathrm{c}, \mathrm{d}}$ & $5.57(1.51)^{\mathrm{a}, \mathrm{c}}$ & $3.81(1.76)^{\mathrm{a}, \mathrm{b}, \mathrm{d}}$ & $5.29(1.71)^{\mathrm{a}, \mathrm{c}}$ \\
\hline Perceived personal intentions to quit smoking & $2.46(1.50)^{\mathrm{b}, \mathrm{c}, \mathrm{d}}$ & $4.40(1.87)^{\mathrm{a}, \mathrm{c}}$ & $3.26(1.68)^{\mathrm{a}, \mathrm{b}, \mathrm{d}}$ & $3.95(1.95)^{\mathrm{a}, \mathrm{c}}$ \\
\hline \multicolumn{5}{|c|}{ Study 3} \\
\hline \multicolumn{5}{|l|}{ Affective Variables } \\
\hline Negative affect & $3.39(1.59)^{b, d}$ & $4.52(1.71)^{\mathrm{a}, \mathrm{c}}$ & $3.46(1.42)^{\mathrm{b}, \mathrm{d}}$ & $4.58(1.60)^{\mathrm{a}, \mathrm{c}}$ \\
\hline Package attractiveness & $3.60(1.44)^{b, c, d}$ & $1.65(.98)^{\mathrm{a}, \mathrm{c}}$ & $3.06(1.27)^{\mathrm{a}, \mathrm{b}, \mathrm{d}}$ & $1.68(1.02)^{\mathrm{a}, \mathrm{c}}$ \\
\hline \multicolumn{5}{|l|}{ Perceived Effectiveness and Intentions to Quit } \\
\hline Encourage other smokers to quit & $2.71(1.39)^{b, c, d}$ & $5.34(1.37)^{\mathrm{a}, \mathrm{c}}$ & $3.98(1.61)^{\mathrm{a}, \mathrm{b}, \mathrm{d}}$ & $5.00(1.49)^{\mathrm{a}, \mathrm{c}}$ \\
\hline Perceived personal intentions to quit smoking & $2.51(1.73)^{\mathrm{b}, \mathrm{d}}$ & $4.60(1.99)^{\mathrm{a}, \mathrm{c}}$ & $2.89(1.47)^{\mathrm{b}, \mathrm{d}}$ & $3.96(1.87)^{\mathrm{a}, \mathrm{c}}$ \\
\hline
\end{tabular}

4.37) than no visual warning $(\mathrm{M}=3.21)$ and results in lower levels of package attractiveness $(M=1.74)$ than no visual warning $(\mathrm{M}=3.74)$.

\section{Perceived Effectiveness and Smokers' Intent-to-Quit Perceptions}

The results show an interaction between univariate message statement and visual warning for both the ability to encourage others to quit smoking $(\mathrm{F}=7.89, p<.01)$ and personal intentions to quit smoking $(\mathrm{F}=6.42, p<.05)$. A plot of the cell means relevant to this interaction appears in Figure 1. This plot indicates that in the absence of visual information on the package (i.e., the status quo in the United States), the package with the verbal warning message displayed on the front of the package is significantly more effective than the package with no message displayed. However, when this visual is included, there is no significant difference between the verbal-warning-message and the no-message conditions. Across these two dependent variables, univariate main effects were significant for the visual factor. As in Study 1, the presence of this specific visual warning suggests that the visual significantly increases the perceived effectiveness of the package both in encouraging other smokers to quit and in affecting participants' personal intentions to quit smoking (Fs $=73.06$ and $21.84, p s<.01$, respectively).

Similar to Study 1, we used contrasts between cell means to examine the different warning label options consistent with FCTC provisions. For the sample of female smokers, the encourage-other-smokers-to-quit mean for the condition that combined a warning statement and a visual warning $(M=5.29)$ is significantly greater than those for the condition with only a warning statement $(\mathrm{M}=3.81, p<.01)$ and the control condition with no warning $(\mathrm{M}=2.78, p<.01)$. However, as the superscripts in Table 2 indicate, the combination of a visual and message statement does not significantly differ from a visual only $(p>.10)$. Finally, as we expected, the visual only and the verbal warning message only are rated as more effective than no warning information at all on the package $(p<.01)$.

As we show in Table 2, although the means are consistently lower across the four conditions for the perceivedpersonal-intentions-to-quit measure, the contrasts between the cell means are similar to the encourage-others-to-quit dependent measure. The means for the condition that combined a verbal statement and a visual warning are significantly greater than the condition with the warning statement only and the control condition with no warning information at all. There is not a significant difference between the condition with only a visual warning and the condition that combined a visual and a message warning.

\section{Discussion}

The results from Study 2 indicate significant effects of the inclusion of the visual warning on package attractiveness and affect. In addition, the package with only the visual warning leads to greater effectiveness in encouraging other female smokers to quit smoking while pregnant than the package with only the U.S. message statement or the package with no warning at all. More important, the combination of message and visual used in this study resulted in stronger personal intentions to quit than both the message statement alone and no warning information at all. The combination of message and visual warning was not significantly different from the package that contained only the visual warning. 
Figure 1. Study 2: The Effect of Graphic Visual and Message Statement Warnings on Perceived Effectiveness

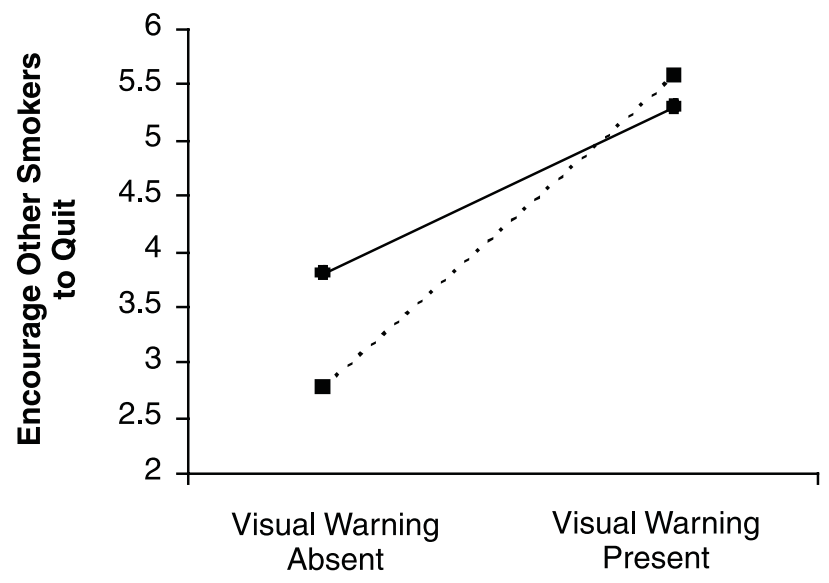

Visual Warnings
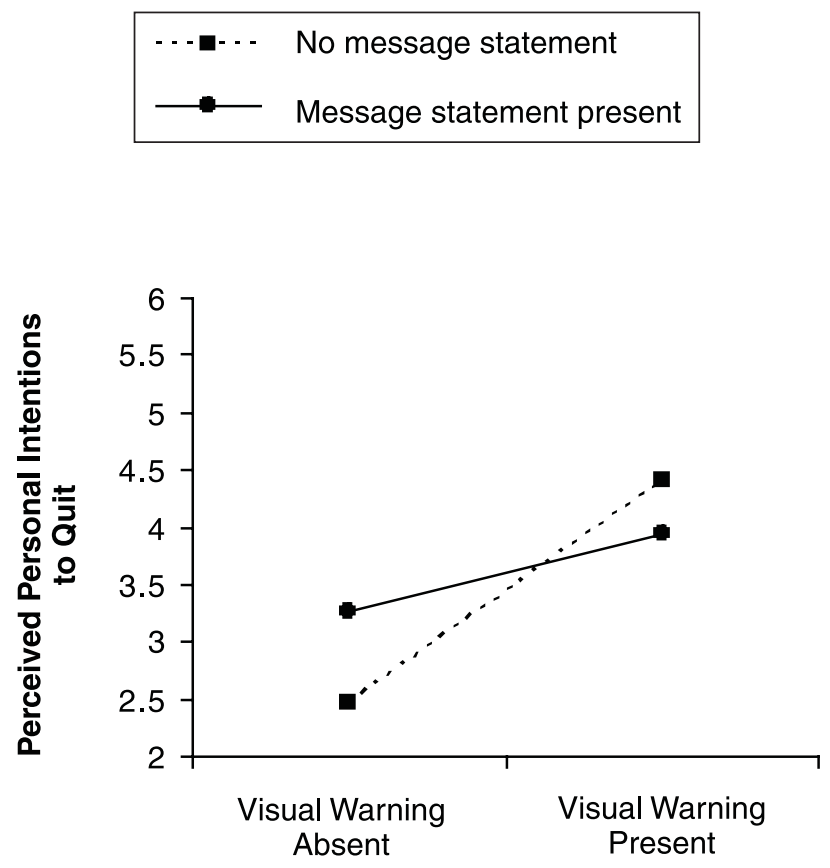

Visual Warnings

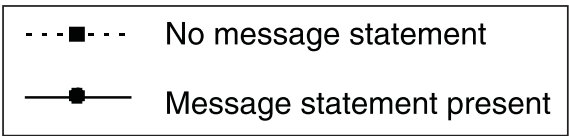

Both Studies 1 and 2 examined effects for smokers in the United States, in which cigarette packages do not contain visual warning information. Thus, effects related to inclusion of graphic visuals may benefit from a novelty effect due to participants lack of familiarity with such pictures on the package (see Bhalla and Lastovicka 1984). To address this possibility and attempt to replicate the pattern of find- ings from Study 2, we conducted Study 3 with a sample of female smokers residing in Canada. Pictures have been required on the front and back of all cigarette packages sold in Canada since December 2000.

\section{Study 3}

\section{Methodology and Results}

The design, stimuli, procedures, and measures used were identical to those of Study 2. However, in contrast to the U.S. smokers who participated in Study 2, participants in Study 3 were 145 Canadian female smokers who were members of the Web-based panel. Again, participants ranged in age from 18 to 44 . Almost all (98\%) were high school graduates, $60 \%$ had at least some education beyond high school, and $19 \%$ were four-year college graduates. The coefficient alpha for the dependent measures ranged from .84 to .90 and, thus, as in Study 2, were all acceptable.

Cell means for Study 3 appear at the bottom of Table 2. In general, the findings are similar to those from Study 2. Consistent with both prior studies, the interaction between the visual and the message statement warning was nonsignificant for the negative-affect and packageattractiveness dependent variables. Similar to Studies 1 and 2 , the presence of the visual warning on the package resulted in higher levels of negative affect $(\mathrm{F}=18.06, p<.01)$ and lower levels of perceived package attractiveness $(F=62.25$, $p<.01)$ than did the absence of a visual warning. The presence of visual information increased the perceived effectiveness of the package in encouraging other smokers to quit $(\mathrm{F}=54.87, p<.01)$ and increased smokers personal intentions to quit smoking $(\mathrm{F}=24.48, p<.01)$. However, the univariate interaction between the visual warning and the message warning was significant for the measure of ability to encourage other smokers to quit $(\mathrm{F}=10.75, p<.01)$ and marginally significant for the measure of personal intentions to quit $(\mathrm{F}=2.99, p<.10)$. Plots of the means appear in Figure 2. Similar to the plot in Figure 1, this interaction indicates that when this visual warning was not present, the verbal warning statement was more effective than when there was no statement. However, when this visual warning was present, we observed no difference between the verbalmessage and no-message conditions (refer to specific cell comparisons in Table 2 and subsequent descriptions). Additional tests assessed contrasts between cell means to examine the different warning label options recommended by the FCTC; superscripts in Table 2 are relevant to these tests. For perceived personal intentions to quit, the mean for the combined condition of the message and the visual warning $(\mathrm{M}=$ $3.96)$ is greater than those for the condition in which there was only a verbal message $(\mathrm{M}=2.89, p<.01)$ and the condition in which there was no warning $(\mathrm{M}=2.51, p<.01)$. For these data, there is not a significant difference between combining a message and visual warning and using only a visual warning $(\mathrm{M}=4.60, p>.10)$.

The pattern of results was similar for effects on the encourage-other-smokers-to-quit dependent variable. The results show that the mean for the condition that combined the U.S. statement and the visual warning is significantly greater than that for the condition that used only the U.S. warning statement. As we show in Table 2, the general pattern of means and contrast findings for the Canadian smok- 
ers, who have been exposed to visual warnings on packages, is consistent with the U.S. smokers in Study 2.

\section{General Discussion}

With approximately five million tobacco-related deaths per year, tobacco use is the leading cause of preventable death

Figure 2. Study 3: The Effect of Graphic Visual and Message Statement Warnings on Perceived Effectiveness

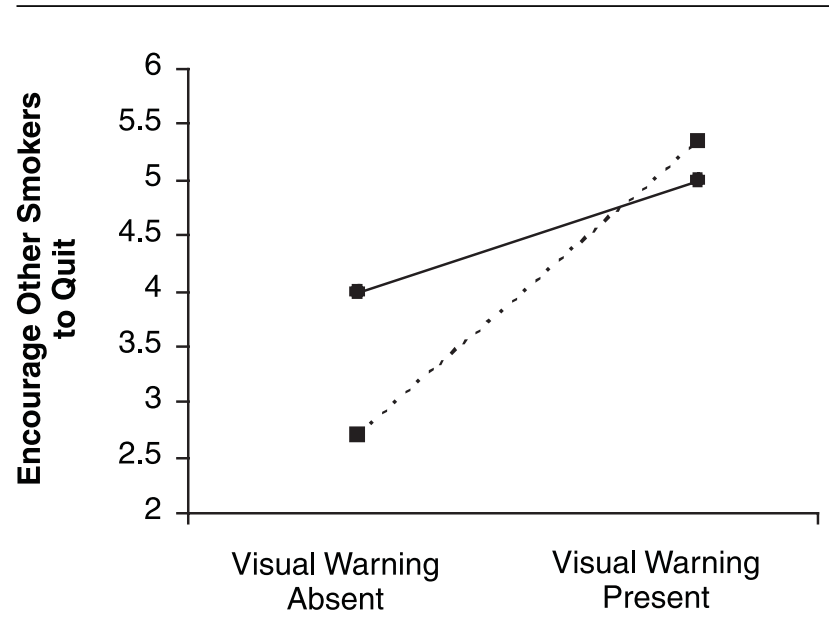

Visual Warnings
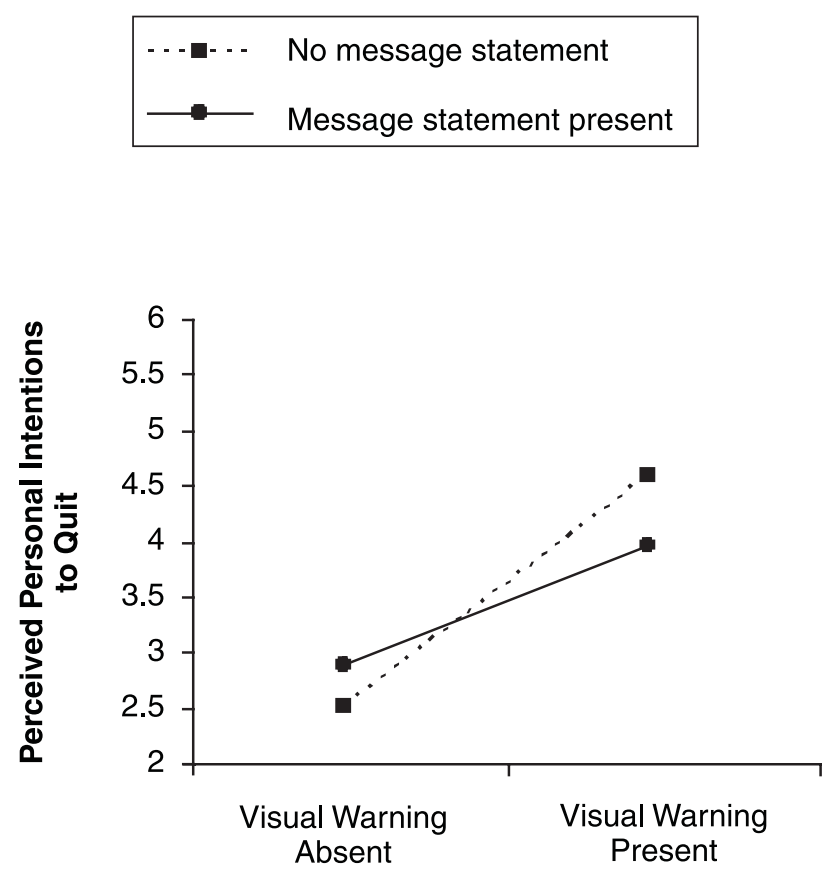

Visual Warnings

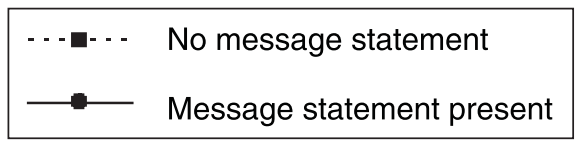

in the world today (WHO 2005). On May 21, 2003, the WHO's 192 members unanimously approved the world's first public health treaty, the FCTC. Among the key elements of the treaty are important restrictions related to packaging and labeling of tobacco products. Warning information may be presented in the form of either text or pictures and must take up a minimum of $30 \%$ of the principal package display areas. Given these forthcoming changes in warnings, we examined cigarette packages with only text warnings, only visual information warnings, and the combination of text and visual warnings in three forced-exposure studies. Study 1 focused on young adults who were current smokers, and Studies 2 and 3 examined adult female smokers who reside both in the United States (in which visual warnings are not used) and in Canada (in which visual warnings are used).

\section{Key Findings and Implications for Public Policy}

Across the three studies, we found that the inclusion of two specific graphic visuals depicting the health consequences of smoking affected consumer-related evaluations. Within the forced-exposure context of our studies, the addition of these visual warnings to package stimuli displaying the two U.S. warning statements resulted in greater reported personal perceived intentions to quit smoking and the ability of the package to encourage other smokers to quit. In addition, the findings indicated that including these particular graphic visuals on the package decreased perceptions of package attractiveness and increased negative affect.

Although the findings across the three studies are consistent in showing that the visuals used in our three studies would be beneficial from a policy standpoint, it is important to recognize a few differences among the studies. The combination of the message statement and the visual information used in Study 1 increased current smokers' reports of perceived quitting intentions more so than both (1) the warning statement only and (2) the visual warning only. However, in Studies 2 and 3, effects on evaluations and intentions of the combination of the message and the visual warning did not differ significantly from the use of only the visual information. It is possible that variations in the type of message (e.g., effects on the health of babies from mothers' smoking behavior compared with specific health problems related to smoking for the individual) and the accompanying graphic visuals used led to some differences in the pattern of findings. Thus, further research is warranted on the effects of specific visual warning information on cigarette packages for other message statement types and other study contexts.

The purpose of this research was to assess the addition of specific graphic visuals in the context of verbal warnings currently used in the United States. The findings across the three studies related to this goal were strong and consistent and, therefore, potentially relevant and important for public health policy. Across the three studies, packages that included both the visuals and the U.S. warning message statements were consistently rated as more effective than packages that included only message statement warnings at encouraging smokers to quit smoking and influencing smokers' personal intentions to quit. Thus, the results from our forced-exposure studies suggest that the inclusion of these specific graphic pictures on cigarette packages can be 
beneficial from a policy standpoint. These findings are also consistent with more general cross-sectional surveys of adult smokers in Canada that indicate a positive effect of the use of graphic cigarette warnings on perceived likelihood of quitting and thinking about the health risks of smoking (Hammond et al. 2004).

Our findings offer potential implications for countries that are considering changes to cigarette warnings based on the FCTC options. In the case of the package visuals and U.S. warning statements we examined across our studies and for the current dependent variables and study contexts, a consistent pattern of findings indicates that inclusion of visual information is desirable from a public health perspective. This is consistent with results from Hammond and colleagues' (2004, p. 1444) survey of Canadian smokers in which they conclude that cigarette "warning labels should adopt vivid and striking features that increase their salience among smokers." Again, we believe that additional research that examines other message statement types and visual warnings (e.g., from Canada and the European Union) is warranted. ${ }^{7}$

\section{Study Limitations and Further Research}

We acknowledge several limitations and suggest possible directions for further research. In general, the experimental context and setting may affect the generalizability of specific findings to the consumer marketplace. For example, because our studies took place in a controlled experimental setting, participants' attention was directed toward the package. Participants viewed the warning stimuli immediately before responding to the measures. Further research might vary this approach by presenting the warning information in a more natural setting among competing products to limit the effects due to forced exposure to the stimuli. In addition, because of the controlled setting of our study, our findings in Studies 1 and 2 may have been driven, at least in part, by the participants' immediate reaction to a more novel stimulus (i.e., graphic pictures on the front of the cigarette package). In an attempt to address this limitation, the sample in Study 3 used Canadian smokers who have been exposed to graphic visuals on packages for several years. However, future studies might also attempt to capture smokers'

\footnotetext{
${ }^{7}$ As a reviewer noted, it would be worthwhile for further research to examine the effects of other visuals for warning messages that appear more direct and stronger, such as some messages currently in use in Canada.
}

responses in a context in which the participants' attention is not focused solely on the cigarette package.

Our study was limited to the examination of the perceived effectiveness of only two specific U.S. warning statements and two specific visuals. As we indicated previously, the particular pattern of results may not extend to other visuals or warning statements. Although analyses for all U.S. warnings in use and the array of warning statements and visuals in use in Canada and other countries are likely to be too broad for controlled, between-subjects experiments, there may be interest in other possible combinations of visual warnings and statements (e.g., the influence of visuals in conjunction with the other U.S. messages currently used). Given the flexibility of the treaty in terms of package and labeling to include warnings in the form of visuals and statements either in combination or in separate form, addressing the effects across various combinations of visual and statement warning stimuli appears warranted.

An important contribution to the study of warning effectiveness is the examination of effects on actual behavior (e.g., Cox et al. 1997). Our studies investigate important intermediate effects, but these effects may not generalize to long-term smoking-related behavior. Further research might consider the effects of the manipulations in conjunction with measures of subjective norms and self-efficacy. In addition, asking smokers to predict how other smokers may react or how they may react themselves to exposure to package stimuli is a limitation of the current research, given that such predictions may be difficult to make. We acknowledge that when dealing with a challenging behavior such as smoking, reported intentions to quit (as measured in our study) might be different from actively trying to quit or actually quitting. Although studies gauging the effects of package modifications on long-term smoking behavior may be difficult in the current regulatory environment of the United States, quasiexperimental studies for countries that have changed packaging requirements in recent years (e.g., Canada, Australia) would complement more controlled studies of package adaptations (Fong 2003).

In summary, given the magnitude of the world's health problems related to smoking, we believe that our investigation of alternative FCTC package options provides useful information to the public health community. Specifically, our primary finding that the addition of visual warning information can significantly increase smokers' perceived intentions of quitting compared with statements alone is likely to be helpful in better understanding the approaches to take in the difficult battle against worldwide smoking. 
Appendix. Selected Message and Visual Conditions Used
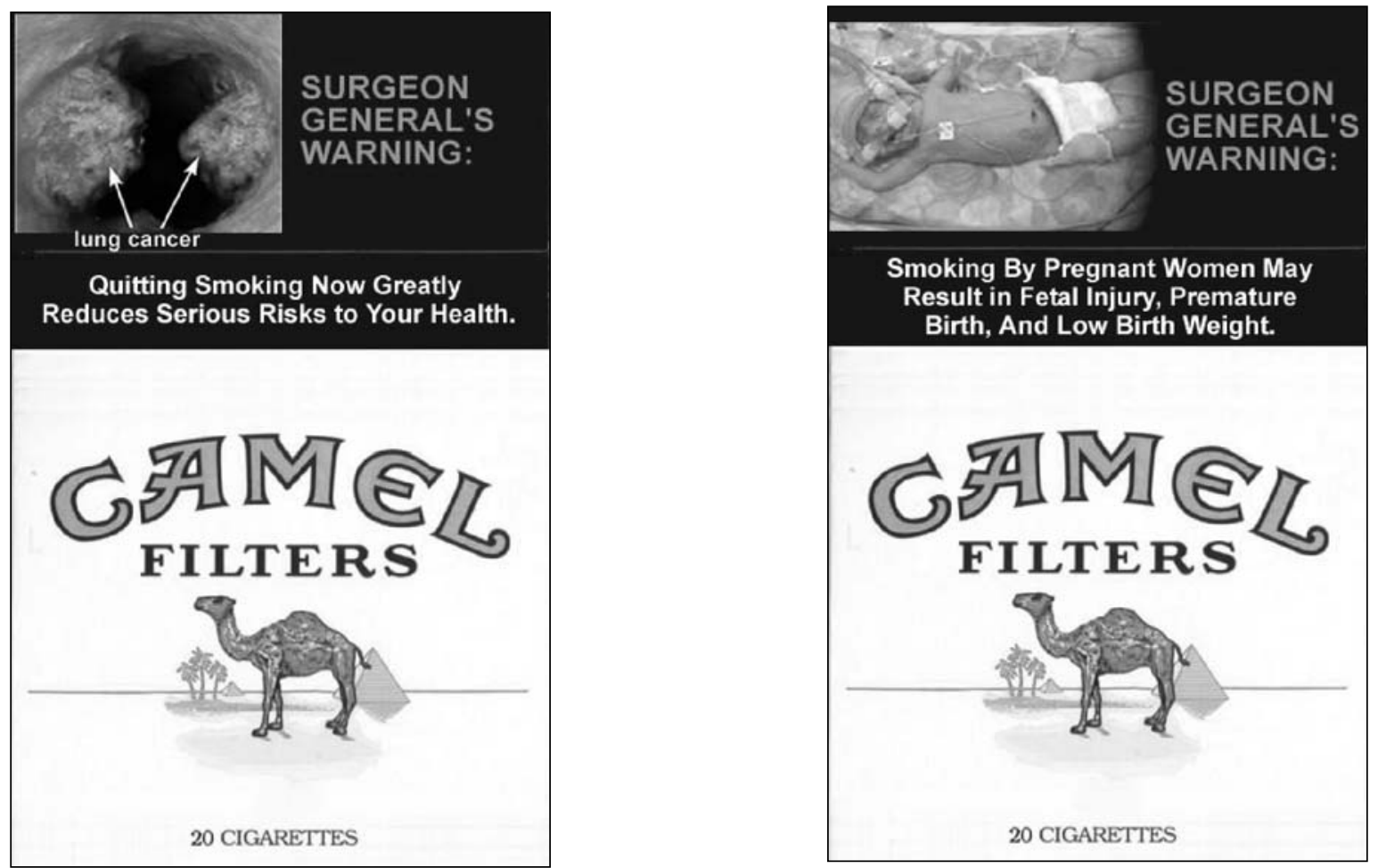

\section{References}

Agres, Stuart, Julie A. Edell, and Tony M. Dubitsky (1990), Emotion in Advertising: Theoretical and Practical Explorations. New York: Quorum Books.

Andrews, J. Craig and Thomas J. Maronick (1995), "Advertising Research Issues from FTC Versus Stouffer Foods Corporation," Journal of Public Policy \& Marketing, 14 (Fall), 301-309.

Argo, Jennifer J. and Kelley J. Main (2004), "Meta-Analysis of the Effectiveness of Warning Labels," Journal of Public Policy \& Marketing, 23 (Fall), 193-208.

Aspect Consortium (2004), Tobacco or Health in the European Union: Past, Present and Future, (accessed February 10, 2005), [available at http://www.ensp.org/publications/library].

Beltramini, R.F. (1988), "Perceived Believability of Warning Label Information Presented in Cigarette Advertising," Journal of Advertising, 17 (1), 26-32.

Bettman, James R., John W. Payne, and Richard Staelin (1986), "Cognitive Considerations in Designing Effective Labels for Presenting Risk Information," Journal of Public Policy \& Marketing, 5, 1-28.

Bhalla, Gaurav and John L. Lastovicka (1984), "The Impact of Changing Cigarette Warning Message Content and Format," in Advances in Consumer Research, Vol. 11, T.C. Kinnear, ed. Provo, UT: Association for Consumer Research, 305-310.

CDC (2005a), "Adult Cigarette Smoking in the United States: Current Estimates," (December), (accessed August 1, 2006), [available at http://www.cdc.gov/tobacco/factsheets/AdultCigarette Smoking_FactSheet.htm].

(2005b), "Cigarette Smoking Among Adults: United States 2004," (accessed July 31, 2006), [available at http://www. cdc.gov/mmwr/PDF/wk/mm5444.pdf].

Cohen, Joel B. (2000), "Playing to Win: Marketing and Public Policy at Odds over Joe Camel," Journal of Public Policy \& Marketing, 19 (Fall), 155-67.

Commonwealth of Australia Law (2005), "Trade Practices (Consumer Product Information Standards) (Tobacco) Regulations 2004," (October 10), (accessed July 28, 2006), [available at http://www.comlaw.gov.au/ComLaw/Legislation/Legislative InstrumentCompilation 1.nsf/0/B3781D693E67CC9ACA 25709D001954B6/\$file/TradePracConProdInfoStdTobacco. pdf].

Cox, Eli P., III, Michael S. Wogalter, Sara L. Stokes, and Elizabeth J. Tipton Murff (1997), "Do Product Warnings Increase Safe Behavior? A Meta-Analysis," Journal of Public Policy \& Marketing, 16 (Fall), 195-205.

Environics Research Group (2001), "Evaluation of New Warnings on Cigarette Packages," prepared for Canadian Cancer Society, (accessed July 29, 2006), [available at: http://129.33.170.32/ vgn/images/portal/cit_776/35/20/41720738niw_labelstudy.pdf]. 
(2003), "Tobacco Pack Information," (December), (accessed July 31, 2006), [available at http://web.worldbank. org/WBSITE/EXTERNAL/TOPICS/EXTHEALTHNUTRITIONANDPOPULATION/EXTPHAAG/0, , contentMDK:20799704 menuPK:1314842 pagePK:64229817 piPK: 64229743 theSitePK:672263,00.html].

Federal Cigarette Labeling and Advertising Act (1965), 15 U.S.C. $\S \S 1331-41$.

Fisher, Paul M., Dean M. Krugman, James E. Fletcher, and Richard J. Fox (1993), “An Evaluation of Health Warnings in Cigarette Advertisements Using Standard Market Research Methods: What Does It Mean to Warn?" Tobacco Control, 2 (4), 279-85.

Fong, Geoffrey T. (2003), "International Tobacco Control Policy Evaluation Project: Conceptual Foundation and Research Methods" paper presented to the International Tobacco Control Research Team at the World Conference on Tobacco, Helsinki, Finland (August 2-8).

Frey, K.P. and A.H. Eagly (1993), "Vividness Can Undermine the Persuasiveness of Messages," Journal of Personality and Social Psychology, 65 (1), 32-44.

Goldberg, Marvin E., John Liefeld, Judith Madill, and Harrie Vredenburg (1999), "The Effect of Plain Packaging on Response to Health Warnings," American Journal of Public Health, 89 (September), 1434-35.

Hammond, Dave, Geoffrey T. Fong, Paul W. McDonald, K. Stephen Brown, and Roy Cameron (2004), "Graphic Canadian Cigarette Warning Labels and Adverse Outcomes: Evidence from Canadian Smokers," American Journal of Public Health, 94 (August), 1442-45.

Hirschman, Elizabeth C. and Barbara B. Stern (1999), "The Roles of Emotion in Consumer Research," in Advances in Consumer Research, Vol. 26, Eric Arnould and Linda Scott, eds. Provo, UT: Association for Consumer Research, 4-11.

Holbrook, Morris B. and Rajeev Batra (1987), “Assessing the Role of Emotions as Mediators of Consumer Response to Advertising," Journal of Consumer Research, 14 (December), 404-420.

Kisielius, Jolita and Brian Sternthal (1984), "Detecting and Explaining Vividness Effects in Attitudinal Judgments," Journal of Marketing Research, 21 (February), 54-64.

Kotler, Phillip and Kevin Lane Keller (2006), Marketing Management, 12th ed. Upper Saddle River, NJ: Pearson Education.

Maheswaran, Durairja and Joan Meyers-Levy (1990), “The Influence of Message Framing and Issue Involvement," Journal of Marketing Research, 27 (August), 361-67.

Maronick, Thomas J. (1991), "Copy Tests in FTC Deception Cases: Guidelines for Researchers," Journal of Advertising Research, 31 (6), 9-17.

Martens, Debra (2002), "Graphic Tobacco Warnings Having Desired Effect," Canadian Medical Association Journal, 166 (11), 1453.

Miniard, Paul W., Sunil Bhatla, Kenneth R. Lord, Peter R. Dickson, and H. Rao Unnava (1991), "Picture-Based Persuasion Processes and the Moderating Role of Involvement," Journal of Consumer Research, 18 (June), 92-107.
Mitchell, Andrew A. and Jerry C. Olson (1981), "Are Product Attribute Beliefs the Only Mediator of Advertising Effects on Brand Attitude?" Journal of Marketing Research, 18 (August), 318-33.

Netemeyer, Richard G., J. Craig Andrews, and Scot Burton (2005), "Effects of Antismoking Advertising-Based Beliefs on Adult Smokers' Consideration of Quitting," American Journal of Public Health, 95 (6), 1062-1066.

Nunnally, Jum C. and Ira H. Bernstein (1994), Psychometric Theory, 3d ed. New York: McGraw-Hill.

Perreault, William D. and E. Jerome McCarthy (1999), Basic Marketing: A Global-Managerial Approach, 13th ed. Boston: Irwin/ McGraw-Hill.

Runyon, Kenneth E. (1979), Advertising and the Practice of Marketing. Columbus, $\mathrm{OH}$ : Merrill.

Scott, Linda M. and Rajeev Batra (2003), Persuasive Imagery: A Consumer Response Perspective. Mahwah, NJ: Lawrence Erlbaum Associates.

Shimp, Terence A. (2007), Advertising, Promotion and Other Aspects of Integrated Marketing Communications, 7th ed. Mason, OH: Thomson South-Western.

Slovic, Paul (2001), "Cigarette Smokers: Rational Actors or Rational Fools?" in Smoking: Risk, Perception, \& Policy, Paul Slovic, ed. Thousand Oaks, CA: Sage Publications, 97-124.

Smith, Ruth A. (1991), "The Effects of Visual and Verbal Advertising Information on Consumers' Inferences," Journal of Advertising, 20 (December), 13-24.

Stewart, David W., Valerie S. Folkes, and Ingrid Martin (2001), "Consumer Response to Warnings and Other Types of Product Hazard Information: Future Public Policy and Research Directions," in Handbook of Marketing and Society, Paul N. Bloom and Gregory T. Gundlach, eds. Thousand Oaks, CA: Sage Publications, 335-71.

Taylor, S.E. and S.C. Thompson (1982), "Stalking the Elusive 'Vividness' Effect,” Psychological Review, 89 (2), 155-81.

Underwood, Robert (1996), "Building Brand Equity Through Packaging: A Multi-Methodological Perspective," in Advances in Consumer Research, Vol. 23, Kim P. Corfman and John G. Lynch Jr., eds. Provo, UT: Association for Consumer Research, 209.

Watson, David, Lee Anna Clark, and Auke Tellegren (1988), "Development and Validation of Brief Measures of Positive and Negative Affect: The PANAS Scale," Journal of Personality and Social Psychology, 54 (6), 1063-1070.

WHO (2003), WHO Framework Convention on Tobacco Control, (accessed August 1, 2006), [available at http://www.who.int/ tobacco/fctc/text/en/fctc_en.pdf].

(2005), "Why Is Tobacco a Public Health Priority?" (accessed August 28, 2005), [available at http://www.who.int/ tobacco/health_priority/en/index.html].

World Bank (1999), "Curbing the Epidemic: Governments and the Economics of Tobacco Control," (accessed August 2, 2003), [available at http://www1.worldbank.org/tobacco/book/html/ cover2a.html]. 
Copyright of Journal of Public Policy \& Marketing is the property of American Marketing Association and its content may not be copied or emailed to multiple sites or posted to a listserv without the copyright holder's express written permission. However, users may print, download, or email articles for individual use. 